\title{
Práticas discursivas delimitadoras de conteúdos: estudo de ementas da formação profissional de professor de línguas
}

\author{
Discursive practices which are delimiters of contents: \\ a study of syllabuses of professional education of language teachers
}

Vera Lucia de Albuquerque Sant'Anna

Universidade do Estado do Rio de Janeiro - Rio de Janeiro - Rio de Janeiro - Brasil

$\diamond$

\begin{abstract}
Resumo: Neste artigo, discutimos uma opção para pensar caminhos a serem postos em relação: partir de uma concepção discursiva de linguagem em busca de um diálogo com a perspectiva ergológica de estudos sobre o trabalho, tendo como foco de estudo ementas de disciplinas do currículo de Letras de uma instituição específica. Esse recorte pretende apontar tendências à aproximação e afastamento da situação de trabalho do professor de ensino superior, a partir da observação de conteúdos validados por ementas de línguas, práticas como componentes curriculares e estágios. Como conceitos norteadores da análise, ressaltamos, no campo da análise do discurso (MAINGUENEAU, [1984] 2005), o de memória discursiva (ACHARD et al., 1999) e, no campo dos estudos do trabalho, (SCHWARTZ, 2012), os de epistemicidades, aderência e desaderência. A proposta aponta nas ementas traços discursivos que remontam a memórias que alimentam valores, atribuídos a modos de conceptualizar ensino de língua, língua, e, como consequência, papel do professor.
\end{abstract}

Palavras-chave: Formação; Trabalho; Professor; Memória discursiva; Desaderência/aderência

\begin{abstract}
In this paper, we discuss a suggestion for thinking pathways to be put in relation: to part from a discursive conception of language for searching for a dialog with the ergological perspective of studies about work, focusing on the syllabuses of the disciplines in the curriculum of the Liberal Arts (Faculty of Language) in a specific institution. Such section is intended to highlight tendencies to approaching to or receding from the work situation of the professor, parting from the observation of validated contents for language syllabuses, practices as curriculum components and training. As the guiding concepts of analysis, we point out, in the field of discourse analysis (MAINGUENEAU, [1984] 2005), the discursive memory (ACHARD et al, 1999), and in the field of work studies (SCHWARTZ, 2012), those of epistemicities, "adherence" and "nonadherence". The proposal reveals in the syllabuses discursive traces that rebuild memories that feed values assigned to ways of conceptualizing language teaching, language, and as a consequence, the teacher's role.
\end{abstract}

Keywords: Education; Work; Teacher; Discursive memory; Adherence/nonadherence

\section{A linguagem não é feita para que se acredite nela, mas para obedecer e fazer obedecer.}

(DeleuZe e GuATtari, 2011, p. 12)

\section{Introdução}

Após pouco mais de dez anos da edição das legislações que organizam a reforma das licenciaturas no Brasil e no ano em que está tramitando o novo Plano Decenal de Educação (o último foi válido até 2011), é importante que a Universidade reveja seus parâmetros organizadores da formação de professor para a educação básica. Existem no Brasil cerca de 2 milhões de professores que atuam nas escolas de Educação Básica, conforme Anuário Brasileiro de Educação Básica 2013. Apesar desse contingente, há um déficit importante de professores para 
esse nível de ensino, não só no nosso país ${ }^{1}$, mas em todo o mundo ${ }^{2}$.

Diante desse quadro deficitário, provocado por inúmeros fatores de naturezas muito variadas, queremos acentuar a discussão sobre a formação profissional do professor de línguas nos cursos de Letras. O grande desafio de um dos papéis centrais da Universidade é a formação profissional que oferece a seus estudantes, em todas as carreiras que fazem parte do conjunto de cursos de graduação da instituição. Entre essas formações profissionais está a de professor do ensino básico, que para graduar-se deverá cursar licenciatura, aqui entendida tal como propõe o Parecer CNE/CP nº 28/2001, de 02/10/2001:

\begin{abstract}
A graduação de licenciatura ao visar o exercício profissional tem como primeiro foco as suas exigências intrínsecas, o que se espera de um profissional do ensino face aos objetivos da educação básica e uma base material e temporal que assegure um alto teor de excelência formativa. [...] O ser professor não se realiza espontaneamente. Na formação do ser professor, é imprescindível um saber profissional, crítico e competente e que se vale de conhecimentos e de experiências.
\end{abstract}

Logo, a licenciatura é uma formação profissional e por essa razão precisa buscar um equilíbrio entre a oferta de disciplinas consideradas como responsáveis por apresentar os conhecimentos específicos da área ${ }^{3}$ e aquelas dedicadas à atuação do futuro professor em sala de aula do ensino básico. A legislação citada ressalta que para desenvolver "um saber profissional, crítico e competente" é preciso aliar "conhecimentos e experiências". Porém, que caminhos teóricos e metodológicos nós professores universitários, que atuamos na formação do profissional professor do ensino básico, temos a nossa disposição para buscar aliar esses dois campos - "conhecimentos" e "experiência" - sem que nenhum dos dois seja visto de forma independente e mais valorizado ou desvalorizado que o outro? Para este artigo, vamos apresentar uma opção para pensar caminhos a serem postos em discussão: partir

\footnotetext{
"Brasil tem um déficit de 300 mil professores na Educação Básica", conforme notícia divulgada no site < http://www.todospelaeducacao. org.br/comunicacao-e-midia/educacao-na-midia/27316/opiniao-faltamprofessores/>

2 "A agência [Unesco] estima que 1,6 milhão de professores adicionais serão necessários para alcançar a educação básica universal até 2015 , e este número vai subir para 3,3 milhões em 2030, de acordo com um relatório publicado pelo Instituto de Estatísticas da UNESCO", conforme $<$ http://www.onu.org.br/sao-necessarios-mais-de-5-milhoesde-professores-em-todo-o-mundo-ate-2030-diz-unesco/>.

3 Em que pese a dificuldade de definir o que seriam esses conhecimentos, já que cada instituição pode encontrar o seu próprio corpo conceitual valorizado como específico da área, existe uma tradição que orienta os conteúdos dados como necessários para essa formação, mas existe espaço para outras propostas
}

de uma concepção discursiva de linguagem em busca de um diálogo com a perspectiva ergológica de estudos sobre o trabalho, tendo como foco de estudo ementas de disciplinas de línguas e de práticas e estágios do currículo de Letras (de uma instituição específica). Esse recorte é parte de um projeto que iniciou com a análise do Projeto Político Pedagógico do Instituto de Letras da IES ${ }^{4}$; prosseguiu com análise do fluxograma implementado com a reforma, em comparação com o anterior ${ }^{5}$ e com análise inicial de ementas de língua espanhola e reflexões sobre ementa enquanto gênero de discurso ${ }^{6}$. Encontram-se em andamento estudos sobre entendimento de "prática" em relação ao de "teoria", tendo por base as legislações que tratam dessa dicotomia (os Pareceres CNE/CP no 9/2001 e n⿳- 28/2001) ${ }^{7}$. Portanto, o objetivo deste artigo é expor uma análise de ementas que possa funcionar como ponto de discussão de professores universitários que atuam na formação de licenciaturas em Letras. As ementas trazidas para discussão são de Língua Portuguesa, de Língua Espanhola e de práticas e estágios relacionados à habilitação dupla em Português-Espanhol, na IES em estudo.

\section{Ponto de partida: a perspectiva discursiva e o diálogo desejado com a perspectiva ergológica}

A compreensão de ementa na situação acadêmica costuma considerar que se trata de uma descrição que "resume o conteúdo conceitual ou conceitual / procedimental de uma disciplina" 8 . Portanto, esse resumo descritivo funciona como um registro de algo motivado por uma decisão anterior, que passa a circular como a fonte de consulta oficial sobre aquilo que um profissional deverá saber para ser considerado apto a exercer a sua profissão. A ementa ocupa, então, papel de destaque nos modos de organizar e delimitar o que compete a cada disciplina incluir como sendo de sua responsabilidade tratar e discutir. Esse recorte das disciplinas se propõe a oferecer tanto ao professor como ao estudante espaços de conhecimento previamente decididos como relevantes e

\footnotetext{
4 Para maiores detalhes, ver SANT'ANNA, V. L. A., SOUZA, A. M. R. O conceito de exercício profissional no PPP do IL-UERJ. In: XIV Congresso Brasileiro de Professores de Espanhol, 2013, Niterói. Anais do XIV Congresso Brasileiro de Professores de Espanhol. Niterói: APEERJ/UFF, 2013. v. 1. p. 26-40.

5 Dissertação de mestrado de Alice Moraes Rego de Souza, defendida em 2013.

6 Estudo desenvolvido com bolsistas PIBIC, André Lima Cordeiro, Liliane Pereira e Pricilla Prazeres, durante 2011-2012.

7 Dissertação de mestrado em elaboração, por André Lima Cordeiro.

$8<$ http://www.pucrs.br/gpt/ementa.php>; uma das poucas referências encontradas sobre como organizar uma ementa de disciplina, sem, contudo, oferecer nenhuma justificativa para a formatação indicada. A maior parte das referências diz respeito a ementas no campo jurídico, aquelas que funcionam como breve resumo do que trata o texto jurídico em questão.
} 
que, por isso, merecem estar contidos nesse breve texto da ementa. A delimitação do que esse texto ementa da disciplina poderá incluir está diretamente relacionado a prescrições para a formação para o trabalho do professor, no âmbito de uma determinada instituição. Essa delimitação exige compreender que esses documentos constroem sentidos e instituem sujeitos interpelados por posicionamentos discursivos em sujeitos de uma profissão (e de formadores para uma profissão): a força impulsionadora dos discursos, "um discurso diz obliquamente com quais outros discursos pode ser associado" (MAINGUENEAU, [1984]2005, p. 135), implica a ideia de que se fala a partir de um conjunto de traços que não estão imediatamente observáveis, por isso, temos a ilusão de saber sobre o que se fala, é essa ilusão que permite a interpelação a partir de um posicionamento discursivo. Entende-se, então, que a ementa de uma disciplina faz parte de um conjunto de práticas discursivas que a validam e se realimentam, compondo um mapa das práticas sociais responsáveis pela articulação entre discursos e organização institucional. Assim, a ementa de uma disciplina é o registro de saberes valorizados e, como refração, dos apagados, que definem traços identitários para o profissional de Letras que deverá atuar como professor ${ }^{9}$.

Compreendida a noção de ementa a partir dessa perspectiva discursiva, observemos as estabilidades de sua organização composicional, tal como propõem os estudos bakhtinianos de gênero de discurso. Uma das marcas linguísticas da estabilidade organizacional das ementas é o uso de nominalizações. Ou seja, não se indicam explicitamente ações a serem cumpridas, listam-se conteúdos em sequência, não necessariamente relacionados entre si como algo que exigisse relações de causa-consequência. Muitas vezes, a enumeração mistura, inclusive, tendências teóricas diferentes, sem explicitar essa opção. Partindo-se, então, da nominalização como elemento fundamental para a existência de uma ementa, pode-se pensar como Patrick Sériot (1986, apud PACHI FILHO, 2008, p. 315) que "as nominalizações seriam o resultado de operações efetuadas anteriormente à realização do texto no qual elas ocorrem. Elas seriam uma espécie de paráfrase que está em relação com outro enunciado", contudo, nada no uso da nominalização indicaria o sujeito e o objeto da ação. Essa textualidade, baseada no processo de nominalização (PACHI FILHO, 2008; REZENDE, 2007), provoca a submissão da ementa aos efeitos do apagamento do processo de interlocução, no qual teria se manifestado tão somente uma voz de autoridade institucional responsável pela ementa. Essa voz não identificada confere ao enunciado o estatuto de prescrição oficial, ao mesmo tempo que evoca uma memória discursiva, ao mobilizar conceitos que se autorreferenciam.
Esse processo discursivo constrói para as ementas o lugar institucional da memória dos conteúdos disciplinares selecionados como representantes daquilo que merece ser registrado como saberes a serem aprendidos pelo estudante, de modo que este possa vir a atuar profissionalmente como professor. A produção discursiva da ementa, portanto, submetida aos níveis de poder que agem nos embates institucionais e que dominam o que pode ou não ser dito numa ementa, acabam por delimitar as fronteiras de saber que deverá/poderá alcançar o estudante futuro professor.

A formação profissional exige que se levem em consideração problemas relacionados ao trabalho que irá desenvolver o futuro professor. Para fazer uma aproximação a esses problemas, nosso grupo de pesquisa ${ }^{10}$ aproximou-se das propostas desenvolvidas por Schwartz e sua equipe, ao propor a perspectiva ergológica para aprofundar o conhecimento sobre a atividade de trabalho. Neste artigo, nosso foco é a discussão sobre a relação entre visões epistêmicas e ergológicas sobre disciplinas que se aproximam e se afastam da atividade de trabalho (SCHWARTZ, 2002).

$\mathrm{Na}$ abordagem epistemológica da atividade de trabalho, à qual se contrapõe a proposta ergológica, o objeto não é alvo de debate de normas ${ }^{11}$, como se os humanos pudessem ser estudados fora desse debate. São campos que estabelecem conceitos e se organizam em disciplinas, dedicados a construir objetos científicos distanciados das vicissitudes do humano. Em contrapartida, a abordagem ergológica da atividade de trabalho diz respeito ao humano, ao debate de normas exigido pela vida, incorpora a dimensão histórica, a manifestação singular; considera que somos corpos, não escapamos de certas leis gerais, e, ao mesmo tempo, nenhuma parte de nosso corpo pode ser abstraída do debate de normas, porque estas variam conforme as histórias e os diferentes modos de confrontar as normas antecedentes.

A abordagem epistêmica situa-se em uma situação de desaderência, para falar como Schwartz, ou seja, são saberes formais, ensinados na escola, que por seu modo de relacionar-se com a vida são posicionados como distantes, melhor dizendo, desapegados, da situação

\footnotetext{
9 Há vários problemas de ordem institucional no registro e arquivo de ementas. Há versões em processos administrativos que não coincidem, necessariamente, com as versões em site oficial ou no catálogo editado pela unidade de ensino. Portanto, haveria um espaço de discussão sobre legitimidade das versões, mas não nos dedicaremos a esse problema. Usamos para nosso estudo as ementas incluídas em catálogo editado em 2013, pela própria unidade.

10 Remeto, em particular, ao GT ANPOLL Linguagem, Enunciação e Trabalho, que reúne grupos de diversas instituições que pesquisam articulações entre linguagem e trabalho.

11 Sobre os conceitos de debate de normas, normas antecedentes, renormalização, uso de si, corpo-si, sugerimos consultar Schwartz, 2009, capítulo 1.
} 
vivida no trabalho. Naturalmente, há muitos graus de afastamento, desaderência, entre o que se ensina na escola e o que efetivamente se vive no trabalho, conforme os graus de epistemicidade que uma disciplina se atribui. Pode-se dizer que entre esses graus haveria um nível tão forte de afastamento da atividade que provocaria uma desaderência (a "má" desaderência, conforme Schwartz) capaz de impor-se como uma categorização ou codificação, isto é, como se fosse uma norma com estatuto impositivo de uma lei. Esse efeito, fruto de relações de poder, gera-se em função do apagamento da tensão original entre atividade intelectual e atividade vital, como se ambas as atividades não fossem construções dos discursos produzidos no campo e que, ao mesmo tempo, garantem a cada uma sua forma específica de legitimarem-se.

A abordagem ergológica considera que os saberes investidos na história, isto é, em aderência com relação à atividade de trabalho, não têm sua conceptualização pré-definida de modo definitivo pela formação escolar. Isso porque se produzem conceitos em toda atividade de trabalho, mesmo quando não estejam explicitados, esses processos de uma possível formalização conceitual estão sempre como pano de fundo da atividade. Entre esses, podem ser incluídos formas de saberes do corpo, inconscientes (corpo-si), não colocados em linguagem verbal, mas que já são protocolo na experiência do trabalho (uso de si) - sempre a partir do debate de normas. Reforça-se a ideia de que há uma distância ineludível entre o que se prescreve como tarefa e o que se realiza como atividade. "Não se pode governar o trabalho como se fosse possível antecipar o que o trabalhador realiza na atividade" (SCHWARTZ, 2009).

Como desdobramento desse entendimento, pode-se observar que

a oposição epistêmico/ergológico permite conceber a experiência - a da pessoa que trabalha - como uma dupla antecipação, no sentido dado anteriormente: o esforço de conhecimento tende para o epistêmico quando ele visa à generalização, à neutralização do local para identificar os saberes, regras e organização operantes. Inversamente, o esforço de conhecimento tende para o ergológico quando ele procura desneutralizar, se aproximar dos debates de normas, das micro arbitragens em situação. (DURRIVE, 2011, p. 65)

Portanto, com Durrive, podemos afirmar que a produção de conhecimento disciplinar e conceitual, no nosso caso, relacionada à formação profissional, pode se dar mais no campo epistêmico ou no ergológico, e isso nos remete às arbitragens políticas que cada instituição consegue definir como prioritárias para o modo de organizar suas ementas. Retornamos a esse ponto adiante.

Como forma de didatizar sua concepção teórica, Schwartz (2012) sistematiza a sua discussão sobre níveis de epistemicidades, exposta no Quadro 1, que, em diálogo com as noções de aderência e desaderência, podem nos ajudar a compreender modos de organização de formação profissional de professor.

Quadro 1. Níveis de epistemicidades

\begin{tabular}{|c|c|c|}
\hline Campos & Níveis & $\begin{array}{l}\text { Epistemicidades - diversidade de níveis } \\
\text { de desaderência/aderência } \\
\text { (SCHWARTZ, minicurso, PUC/SP, 2012) }\end{array}$ \\
\hline 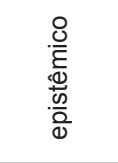 & 1 & $\begin{array}{l}\text { Saberes em desaderência; conhecimentos } \\
\text { que se constroem por conceitos em relação } \\
\text { a um objeto idealizado - apagamento da } \\
\text { subjetividade e da historicidade (por exemplo, } \\
\text { estudos sobre a queda dos corpos). }\end{array}$ \\
\hline \multirow{3}{*}{$\begin{array}{l}\text { 을 } \\
\frac{0}{0} \\
\frac{0}{1}\end{array}$} & 2 & $\begin{array}{l}\text { Conceituação técnica de relativa estabilidade } \\
\text { na produção de normas, regras, procedimentos, } \\
\text { aplicadas à vida social (por exemplo, as regras } \\
\text { relacionadas aos contratos de trabalho). }\end{array}$ \\
\hline & 3 & $\begin{array}{l}\text { Conceituação relacionada às ciências huma- } \\
\text { nas e sociais de estabilidade muito relativa, } \\
\text { considera os ofícios e a importância de uma } \\
\text { entidade coletiva relativamente pertinente } \\
\text { (sujeito e alteridade), tenta explicar a sociedade, } \\
\text { suas instituições, suas relações; busca analisar } \\
\text { os fatos (por exemplo, as teorias das relações } \\
\text { humanas no trabalho). }\end{array}$ \\
\hline & 3bis & $\begin{array}{l}\text { Conceituação de base ergológica, que luta } \\
\text { contra usurpações dos níveis de episte- } \\
\text { micidades que apagam ou enfraquecem o } \\
\text { corpo si, o debate de normas, uso de si; parte } \\
\text { do processo de renormalização, que pode } \\
\text { estar em graus maiores ou menores de ade- } \\
\text { rência. }\end{array}$ \\
\hline
\end{tabular}

O nível 3bis, assim nomeado por não compor propriamente um corpo de disciplinas e, sim, uma visão sobre modos de atuar das disciplinas do nível 3 em aderência à atividade de trabalho, marca uma posição que merece destaque: a noção de usurpação refere-se aos níveis de conceptualização que observa seus objetos de estudo sem considerar o que é próprio da atividade humana, ou seja, usurpa-se, retira-se o humano da atividade, enfraquece-se a experiência vivida, como se ela não fosse capaz de formalizar conceitos para a existência da atividade. Assim como haveria uma "má" desaderência, poderia haver uma "boa", aquela que ao verificar que "a modelização proposta [...] neutraliza os debates de normas", passa por ajustes que diminuem "a distância dos valores estabelecidos localmente [e] se preocupa regularmente com as renormalizações" (DURRIVE, 2011, p.57 e 59).

Portanto, entendemos que é preciso evitar que a preparação para a profissão de professor seja definida pelo controle de conteúdos apresentados de modo totalmente 
dissociado da atividade - no nível epistêmico -, como se fosse algo distante do debate de valores a que está submetido o professor em sua ação cotidiana, como se a prescrição da tarefa fosse o único nível que importasse na concepção do trabalho. O processo de formação profissional, então, precisa considerar o que Vygotsky ([1965]2002) explica sobre a gênese da formação dos conceitos: "para que o processo [da formação de um conceito] comece, terá de surgir um problema que não possa ser resolvido doutra forma, a não ser pela formação de novos conceitos" - o que nos remete diretamente às situações vividas na atividade de trabalho, no nosso caso, do professor, submetidas ao debate de normas entre o que se prescreve e o que efetivamente se encontra como possibilidade de atuação. Por essa razão, é preciso acrescentar, ainda, que "a gênese dos conceitos é um processo criativo e não mecânico e passivo; um conceito surge e toma forma no decurso de uma complexa operação orientada para a resolução do mesmo problema". Isso implica reconhecer que a situação de trabalho, com toda a variabilidade que a faz existir, é o lugar de conceitos em via de conceptualização que devem fazer parte das discussões sobre a formação do professor.

Assim, no caso da formação do professor, acreditamos que um caminho importante é o de diminuir ou tentar diminuir a distância (a desaderência) que as disciplinas do eixo dos saberes formais registram nas suas ementas. Contudo, essa discussão exige uma tomada de posição que requer a participação dos formadores de professores na discussão, para que os possíveis caminhos possam ser delineados e postos em prática por esses formadores, em busca de um coletivo de trabalho - ou seja, que ultrapassemos o nível da reunião formal e que nos aproximemos de objetivos comuns na discussão do que pode ser entendido como conteúdos indispensáveis para a formação do professor em Letras, e dos caminhos para evitar a desaderência conceitual, assim como se encontrem modos de incorporar os diferentes níveis de conceptualização construídos na atividade. Na atividade docente, o professor vai organizar sua ação e mobilizar seus conhecimentos a partir da situação de trabalho que lhe tocou viver, e os formadores de professores, portanto, devem buscar conhecer a situação de trabalho da educação básica para poder propor aquilo que melhor se adequaria às condições de existência da atuação docente, em cada um dos campos disciplinares a que está submetida a organização escolar - seja para reforçá-la, seja para contestá-la.

Como um primeiro momento para pensar caminhos para analisar os níveis de desaderência /aderência de disciplinas oferecidas em uma determinada instituição, apontamos, a seguir, modos de dizer conceitos em ementas, com a finalidade de auxiliar a discutir nossas possibilidades de encaminhamentos.

\section{Ementas do curso de Letras, memória discursiva e perspectiva ergológica: possibilidade de diálogo}

Em matéria publicada na Folha de São Paulo, em 04/08/2013, atribui-se a secretários de educação reunidos em um evento nacional, uma declaração que considera que "a formação universitária dos futuros professores da educação básica é um dos entraves para a melhoria da qualidade do ensino no país". Isso porque "os futuros docentes têm muito contato com teóricos da educação, mas terminam o curso despreparados para enfrentar salas de aulas". Como complemento à matéria que se estende um pouco mais, há alguns quadros com estatísticas. Ressaltamos um deles (em anexo), tendo em vista que aponta a distribuição percentual de disciplinas nos currículos, divididas entre aquelas que representam conhecimentos específicos em Letras $(51,4 \%)$, conhecimentos específicos para a docência $(11,1 \%)$, fundamentos teóricos $(7,8 \%)$, atividades complementares $(5,7 \%)$, conhecimentos sobre sistemas educacionais $(4,1 \%)$, pesquisa e trabalho de conclusão $(3,7 \%)$, conhecimentos de modalidades de ensino $(1 \%)$ e outros saberes $(15,2 \%)$, conforme a fonte consultada pelo jornal ${ }^{12}$.

Não cabe, aqui, detalhar cada item do quadro estatístico, contudo, chama a atenção o fato de que a soma dos conhecimentos específicos, fundamentos teóricos, pesquisa e trabalho de conclusão corresponda a $62,9 \%$ das disciplinas. Não sabemos o que está incluído em outros saberes, mas podemos supor que algum percentual cabe a questões da ordem das disciplinas dos saberes científicos, o que pode aproximar de uns $70 \%$ a ocupação do currículo de formação em licenciatura em Letras com o eixo das disciplinas que, podemos supor, estariam em desaderência em relação à atividade de trabalho. Explicitamente, as disciplinas mais próximas da atividade somam $16,2 \%$. Efetivamente, algo ocorre no entendimento do que é a formação para uma atividade profissional de professor.

$\mathrm{Na}$ instituição que abordamos neste artigo, a distribuição de horas, a partir do que exige a legislação federal (Resolução CNE/CP no 2/2002), é a que se segue no Quadro 2.

\footnotetext{
${ }^{12}$ A pesquisa promovida pela Fundação Carlos Chagas e Victor Civitta, de autoria de GATTI, Bernadete A.; NUNES, Marina M. R.; GIMENES, Nelson A. S.; TARTUCE, Gisela Lobo B. P.; UNBEHAUM, Sandra G. A formação de professores no Brasil. Disponível em: <http://www.fvc. org.br/estudos-e-pesquisas/avulsas/estudos1-3-formacao-professores. shtml?page $=0>$.
} 
Quadro 2. Distribuição de carga horária de disciplinas no curso de Letras da UERJ, após a reforma da licenciatura realizada em 2006

\begin{tabular}{|c|c|c|c|}
\hline \multicolumn{2}{|c|}{ Resolução no 2 CNE/CP 19/02/2002 } & \multicolumn{2}{|c|}{$\begin{array}{l}\text { Licenciatura em Letras } \\
\text { habilitação dupla - UERJ }\end{array}$} \\
\hline \multirow{3}{*}{$\begin{array}{l}\text { Práticas como } \\
\text { componentes curriculares }\end{array}$} & \multirow{3}{*}{400 horas } & \multirow{3}{*}{420 horas } & $\begin{array}{l}90 \text { horas } \\
\text { CAP }\end{array}$ \\
\hline & & & $\begin{array}{l}90 \text { horas } \\
\text { EDU }\end{array}$ \\
\hline & & & $\begin{array}{l}240 \text { horas } \\
\text { ILE }\end{array}$ \\
\hline \multirow{3}{*}{$\begin{array}{l}\text { Estágio curricular } \\
\text { supervisionado }\end{array}$} & \multirow{3}{*}{400 horas } & \multirow{3}{*}{420 horas } & $\begin{array}{l}60 \text { horas } \\
\text { EDU }\end{array}$ \\
\hline & & & $\begin{array}{l}210 \text { horas } \\
\text { CAP }\end{array}$ \\
\hline & & & $\begin{array}{l}150 \text { horas } \\
\text { ILE }\end{array}$ \\
\hline \multirow{2}{*}{$\begin{array}{l}\text { Conteúdos curriculares de } \\
\text { natureza científico-cultural }\end{array}$} & \multirow{2}{*}{1800 horas } & \multirow{2}{*}{2850 horas } & $\begin{array}{l}270 \text { horas } \\
\text { EDU }\end{array}$ \\
\hline & & & $\begin{array}{l}2580 \text { horas } \\
\text { ILE }\end{array}$ \\
\hline $\begin{array}{l}\text { Atividades acadêmico- } \\
\text { científico-culturais }\end{array}$ & 200 horas & 200 horas & \\
\hline TOTAL & 2800 horas & 3890 horas & \\
\hline
\end{tabular}

Comparando-se o que exige como mínimo a legislação, verifica-se que a universidade oferece uma carga horária razoavelmente mais alta que a preconizada $(38,9 \%)$. E sua divisão interna envolve três unidades de ensino: o Instituto de Letras, a Faculdade de Educação e o Colégio de Aplicação ${ }^{13}$. Para este artigo, optamos por demonstrar uma discussão somente sobre algumas ementas das que estão relacionadas ao Instituto de Letras, da habilitação dupla em Português-Espanhol, nossa área de atuação na graduação.

As ementas utilizadas têm como fonte o Catálogo Letras/UERJ (2013). Iniciamos com duas de língua espanhola e duas de língua portuguesa:

Lingua espanhola I: Desenvolvimento da oralidade e introdução à produção/compreensão escrita, com foco nos gêneros discursivos que apresentam características descritivas.

Lingua espanhola II: Desenvolvimento da oralidade e introdução à produção/compreensão escrita, com foco nos gêneros discursivos que apresentam características descritivas.

Língua portuguesa I: O texto - sua construção, gêneros e sentidos. O texto, o contexto e as variáveis da interação verbal. Os usos da língua e seu sentido social:

\footnotetext{
${ }^{13}$ Cada universidade/faculdade pode distribuir internamente as horas exigidas pela legislação conforme seu entendimento do que seria mais adequado. Não há um modelo a ser seguido na divisão de horas/disciplinas entre as unidades de ensino. Sobre esse tema, ver SANT'ANNA; DAHER. "Reforma das licenciaturas: revendo escolhas para a formação para o trabalho de professor em Letras - língua estrangeira", a ser publicado.
}

o coloquial e o formal. A questão da norma padrão. $A$ identidade sociocomunicativa do enunciador e do destinatário e a construção dos sentidos. Os gêneros textuais e os modos de organização textual. Coerência e coesão textuais. A frase e o parágrafo. Atitudes e intenções enunciativas: atos de fala e modalidades da frase. Discurso direto, discurso indireto e indireto livre. Recursos textuais de conexão de frases e de parágrafos.

Lingua portuguesa II: Sintaxe e Semântica do português: a oração e seus termos. Caracterização formal das unidades de sentido (periodo, oração, sintagma, palavra e morfema) e respectiva distribuição hierárquica no sistema da língua. Frase e oração. As espécies de sintagmas, suas funções sintáticas e papeis semânticos. Classes de palavras segundo as posições que ocupam no sintagma. Os meios de concatenação sintagmática: concordância, regência, e colocação. A conversão de orações em sintagmas: orações substantivas, adjetivas e adverbiais. Coordenação de orações no interior do periodo.

Partindo do entendimento de que as ementas são o lugar da memória discursiva de como se dizem os conceitos valorizados que orientam uma certa formação profissional, tecemos comentários sobre os conteúdos registrados nessas ementas. As de língua espanhola I e II iniciam por uma construção de que a oralidade pode ser desenvolvida, ou seja, algo é dado como préexistente à situação de ensino, o que implica que o aluno será levado a um determinado patamar de fala na língua estrangeira, que não é explicitado; a produção/ compreensão escrita, ao contrário, será introduzida, ou seja, se dará o início de um processo; essas ementas, ao fazerem essa apresentação, filiam-se à tradição que sustenta que é possível ensinar uma língua estrangeira dissociando oralidade e produção escrita - memórias discursivas que afirmam que língua é sistema, logo suas estruturas são isoláveis. Contudo, observa-se uma breve entrada a um modo de referenciar uma visão dialógica de linguagem, ao tratar de gêneros de discurso, o que nos faz registrar haver um embate teórico entre tendências. As ementas de língua portuguesa não têm uma distribuição diferente, do ponto de vista da sustentação teórica. $\mathrm{Na}$ Língua I, predomina um recorte sobre aspectos de uma linguística textual, associado a conceitos de gramática normativa; a Língua II está voltada para a gramática normativa. Observa-se uma forte influência de uma visão de língua como sistema, que se organiza a partir de um corpo de conceitos estáveis e controláveis, e, por isso, podem ser isolados certos aspectos de uma língua para serem ensinados fora de qualquer contexto. Percebe-se que todas as ementas entrecruzam tendências que vão desde a desaderência epistêmica, de nível 1, a matizes de (des)aderência ergológica, no sentido de que consideram questões sociais nas suas formas de enunciar os conceitos a serem tratados no eixo dos saberes formais. 
Em relação a ementas de Práticas como componente curricular, lugar de registro para o que se relaciona à memória da profissão, observamos o seguinte conjunto que corresponde às disciplinas obrigatórias:

Prática de ensino em língua espanhola I - A língua espanhola no ensino fundamental e médio: $O$ papel da aprendizagem de línguas estrangeiras na escola pública. A lingua estrangeira no ensino básico. Os documentos propositivos para o ensino de LE de caráter local e nacional. Os estudos sociointeracionistas e dialógicos sobre a linguagem e os de interculturalidade no ensino de LE. Preparação de material específico adequado a diferentes niveis de ensino.

Prática de ensino em língua espanhola II - O ensino do texto literário em língua espanhola: A linguagem literária e não-literária. O papel do texto literário nos principais enfoques metodológicos de ensino de LE. A competência leitora e a competência literária. $O$ discurso literário e o contrato comunicativo. A literatura infanto-juvenil e a de adultos. Confecção e análise de exercícios.

Prática de produção textual I: A polissemia da noção de texto. Estratégias de produção textual. As condições de produção do texto. O conceito de autoria. Registros linguísticos. Gêneros textuais: aspectos textuais e linguísticos. Relações didático-pedagógicas entre leitura e produção textual.

Prática de produção textual II: A polissemia da noção de texto. Estratégias de produção textual. As condições de produção do texto. O conceito de autoria. Gêneros textuais: aspectos textuais e linguísticos. Relações didáticopedagógicas entre leitura e produção textual. A produção textual na escola à luz dos Parâmetros Curriculares Nacionais.

Conforme o Parecer CNE/CP n $28 / 2001$, de 02/10/ 2001, a prática como componente curricular deve ser compreendida como "uma prática que produz algo no âmbito do ensino", ou seja, "há que se distinguir, de um lado, a prática como componente curricular e, de outro, a prática de ensino e o estágio obrigatório definidos em lei". Ou seja, a legislação espera que não haja confusão entre os propósitos de cada disciplina, contudo, como cada conjunto de ementas demonstra, as memórias discursivas convocadas partem de matrizes valorativas não necessariamente coincidentes com as que o parecer propõe; além disso, há muitos âmbitos a serem cobertos pelas práticas como componentes curriculares, observemos trechos do parecer (grifos nossos):

A prática, como componente curricular, que terá necessariamente a marca dos projetos pedagógicos das instituições formadoras, ao transcender a sala de aula para o conjunto do ambiente escolar e da própria educação escolar, pode envolver uma articulação com os órgãos normativos e com os órgãos executivos dos sistemas. Com isto se pode ver nas políticas educacionais e na normatização das leis uma concepção de governo ou de Estado em ação. Pode-se assinalar também uma presença junto a agências educacionais não escolares tal como está definida no Art. 1을 LDB. [...] Professores são ligados a entidades de representação profissional cuja existência e legislação eles devem conhecer previamente. [...] Importante também é o conhecimento de famílias de estudantes sob vários pontos de vista, pois eles propiciam um melhor conhecimento do ethos dos alunos.

Os grifos ressaltam possibilidades de assuntos a virem a compor ementas de disciplinas com essa feição. Ao observar o que as ementas expostas anteriormente registram, observa-se que a Prática de espanhol I ficou caracterizada como prática de ensino, logo, deveria estar atrelada ao estágio que lhe corresponderia, tal como é possível perceber no Parecer 28/2001; já a Prática II está mais próxima de uma prática como componente curricular, já que faz uma discussão de práticas sociais e conteudísticas que não estão atreladas a um estágio que lhe seja simétrico; ainda assim, ambas se aproximam do eixo da aderência à atividade de trabalho. As Práticas de Português I e II propõem conteúdos linguísticos sem uma relação clara com uma atividade profissional; a Prática II aproxima-se dessa atividade ao relacionar a proposta aos PCNs.

Como parte das ementas que remetem à memória da profissão estão as dos estágios. O Parecer CNE/CP nº28/2001, de 02/10/2001, define o Estágio curricular supervisionado de ensino como "o tempo de aprendizagem que, através de um período de permanência, alguém se demora em algum lugar ou ofício para aprender a prática do mesmo e depois poder exercer uma profissão ou ofício". Por esse motivo, o Parecer ressalta que "o estágio curricular supervisionado supõe uma relação pedagógica entre alguém que já é um profissional reconhecido em um ambiente institucional de trabalho e um aluno estagiário", logo, essa situação de aprendizagem "só pode ocorrer em unidades escolares onde o estagiário assuma efetivamente o papel de professor, de outras exigências do projeto pedagógico e das necessidades próprias do ambiente institucional escolar". Não é exatamente assim que se deu o entendimento do estágio. Não vamos incluir as ementas porque não dispomos de espaço suficiente, mas os títulos atribuídos aos estágios são reveladores da compreensão que os organizou, ou seja, de um conjunto de discursos que ocupam o espaço de enunciação dessa memória:

Estágios em Língua Espanhola - O aluno está obrigado a cursar duas entre as disciplinas: Est. Sup. em Lingua Esp. I-Ensino Fundamental e Médio; Est. Sup. em Língua 
Esp. II - Fins Especificos; Est. Sup. Em Lingua Esp. IIIEducação de Jovens e Adultos; Est. Sup. em Lingua Esp. $I V$ - Ensino Não Regular.

Estágios em Língua Portuguesa - O aluno deverá cursar uma das disciplinas: Estágio Supervisionado de Leitura de Textos Acadêmicos; Estágio Supervisionado no Ensino de Português e Redação para Jovens e Adultos; Oficina de Consultoria Linguístico-Gramatical; Oficina de Preparação de Material Didático de Língua Portuguesa; Oficina de Preparação de Originais; Oficina de Revisão Textual.

Observa-se que os títulos dos estágios em língua espanhola remetem a situações escolares, formais e não formais, mas os de língua portuguesa constroem outros sentidos para "estágio". Para esse conjunto caberia uma discussão mais detalhada, que não abordaremos neste artigo.

\section{Breves comentários finais}

Queremos reafirmar que para rever um processo de reforma da licenciatura dessa amplitude, necessariamente, há vários caminhos, por exemplo, partir das imposições da situação de trabalho e incluir o que for possível trazer como matéria a ser conceptualizada; observar as questões conceituais que são a base da proposta da reforma - o nível da desaderência - incorporando-se discussões sobre atividade de trabalho e saberes em aderência. Portanto, tratar da importância e da força de cada conjunto de conceitos de ambos os eixos dos saberes investidos e dos saberes escolares na formação de um professor precisaria considerar que ambos devem estar contemplados de modo claro numa revisão da reforma da licenciatura. Porque para agir num mundo onde a antecipação total (a padronização) é impossível, é necessário alguém capaz de fazer uso de si - para gerir o que não foi pensado antecipadamente. $\mathrm{O}$ ser humano em atividade não cessa de renormalizar, de arbitrar diante do furo de normas ou da inadaptação e da rigidez das normas antecedentes. Agindo assim, ele somente faz aumentar a variabilidade da situação inicial, distanciando cada vez mais da perspectiva - invivível - da padronização. Ele produz, assim, a singularidade, a história, via as renormalizações (SCHWARTZ e DURRIVE, 2009, p. 256). Para os estudos discursivos é o gesto de interpretação que move a nossa vida: não escapamos de tentar compreender o mundo em que nos toca viver, e, ao compreender, (quem sabe?) interferir, perceber aquilo que falha, um esquecimento, um lapso, um furo - uma passagem inesperada, na qual os sentidos, opacos e fugidios, permitem que se possa apostar na busca de uma compreensão sempre parcial. As memórias discursivas convocadas nesse movimento de interpretação trazem uma memória dos saberes valorizados e, consequentemente, dos saberes apagados na formação do professor em Letras. Pêcheux (ACHARD et al., 1999, p. 56) nos esclarece: "[a memória discursiva] é necessariamente um espaço móvel de divisões, de disjunções, de deslocamentos, de retomadas, de conflitos, de regularização... Um espaço de desdobramentos, réplicas, polêmicas e contra-discursos". É dessa matéria que se fazem as ementas.

\section{Referências}

ACHARD, Pierre et al. (Org.). Papel da memória. Tradução e introdução José Horta Nunes. Campinas: Pontes, 1999.

Anuário Brasileiro da Educação Básica 2013. Todos pela Educação e Moderna (org. e edição). Disponível em: <http:// www.moderna.com.br/lumis/portal/file/fileDownload.jsp?file $\mathrm{Id}=8 \mathrm{~A} 8 \mathrm{~A} 8 \mathrm{~A} 833 \mathrm{~F} 33698 \mathrm{~B} 013 \mathrm{~F} 346 \mathrm{E} 30 \mathrm{DA}$ 7B17 $>$. Consultado em: 01 nov. 2013.

BAKHTIN, Mikhail. Estética da criação verbal. Tradução a partir do francês de Maria Ermantina Galvão G. Pereira. São Paulo: Martins Fontes, 1995.

BRASIL. Parecer CNE/CP no 28, de 02 de outubro de 2001. Dá nova redação ao Parecer $\mathrm{CNE} / \mathrm{CP}^{\circ}$ 21/2001, que estabelece a duração e a carga horária dos cursos de Formação de Professores da Educação Básica, em nível superior, curso de licenciatura, de graduação plena. Brasília.

CATÁlOGO DE LETRAS. Rio de Janeiro, IL/UERJ, 2013.

DELEUZE, Gilles; GUATTARI, Felix. Mil Platôs. Tradução de Ana Lúcia de Oliveira e Lúcia Cláudia Leão. Revisão técnica de Luiz B. L. Orlandi. São Paulo: Editora 34, 2011. v. 2.

DURRIVE, Louis. A atividade humana, simultaneamente intelectual e vital: esclarecimentos complementares de Pierre Pastré e Yves Schwartz. Trab. Educ. Saúde, Rio de Janeiro, v. 9, supl. 1, p. 47-67, 2011.

GATTI, Bernadete A.; NUNES, Marina M.R.; GIMENES, Nelson A. S.; TARTUCE, Gisela Lobo B.P.; UNBEHAUM, Sandra G. A formação de professores no Brasil. Fundação Carlos Chagas. Disponível em: <http://www.fvc.org.br/ estudos-e-pesquisas/avulsas/estudos1-3-formacao-professores. shtml?page $=0>$. Consultado em: 18 set. 2013.

LOPES, Alice Casimiro. Políticas de integração curricular. Rio de Janeiro: EdUerj/Faperj, 2008. v. 1. 184 p.

MAINGUENEAU, Dominique. Gênese dos discursos. Tradução de Sírio Possenti. Curitiba: Criar Edições, 2005.

OLÍMPIO, Hilda de Oliveira. Nominalização, memória discursiva e argumentação. VIII FÓRUM DE ESTUDOS LINGUÍSTICOS, Instituto de Letras da Universidade do Estado do Rio de Janeiro, nov. 2005.

PACHI FILHO, Fernando Felício. Efeitos de sentido da nominalização "privatização" no discurso da imprensa. Signótica (UFG), v. 20, p. 307-331, 2008.

REZENDE, Letícia Marcondes. Nominalização e valores referenciais. Estudos Linguísticos, Araraquara, n. 36. Disponível em: <http://gel.org.br/4publica-estudos-2007/sistema06/25. PDF>. 
SANT'ANNA, Vera. L.A.; SOUZA e SILVA, Maria Cecília P. Trabalho e prescrição: aproximações ao problema a partir dos estudos da linguagem. Revista Matraga, Rio de Janeiro, v. 14, n. 20, p. 77-99, jan.-jun. 2007.

SCHWARTZ, Yves; DURRIVE, Louis. Trabalho e ergologia: conversas sobre a atividade humana. 2. ed. Tradução de Jussara Brito, Milton Athayde et al. Organizadores da edição brasileira: Milton Athayde e Jussara Brito. Niterói: Ed. da UFF, 2009.

SCHWARTZ, Yves. A experiência é formadora? Tradução de Daisy Moreira Cunha e revisão da tradução de Gilberto Icle. Rev. Educação e Realidade, jan. 2010.
SCHWARTZ, Yves. Anotações do minicurso ministrado no LAEL-PUC/SP, 2012.

TAKAHASHI, Fábio. Muita teoria e pouca prática formam os professores. Folha de São Paulo, 04 de agosto de 2013. Disponível em: <http://www1.folha.uol.com.br/educacao/2013/ 08/1321237-formacao-do-professor-tem-muita-teoria-e-poucapratica.shtml>. Consultado em: 15 set. 2013.

VYGOTSKY. (1965). Pensamento e linguagem. Tradução do inglês: Jeferson Luiz Camargo. São Paulo: Martins Fontes, 2002. Cap. 5. Gênese e estudo experimental da formação dos conceitos. Disponível em: <http://www.marxists.org/portugues/ vygotsky/ano/pensamento/cap05.htm/>.

\section{ANEXO I}

\section{OS CURRÍCULOS DAS CARREIRAS DOCENTES}

Conhecimentos teóricos ocupam maior parte dos cursos

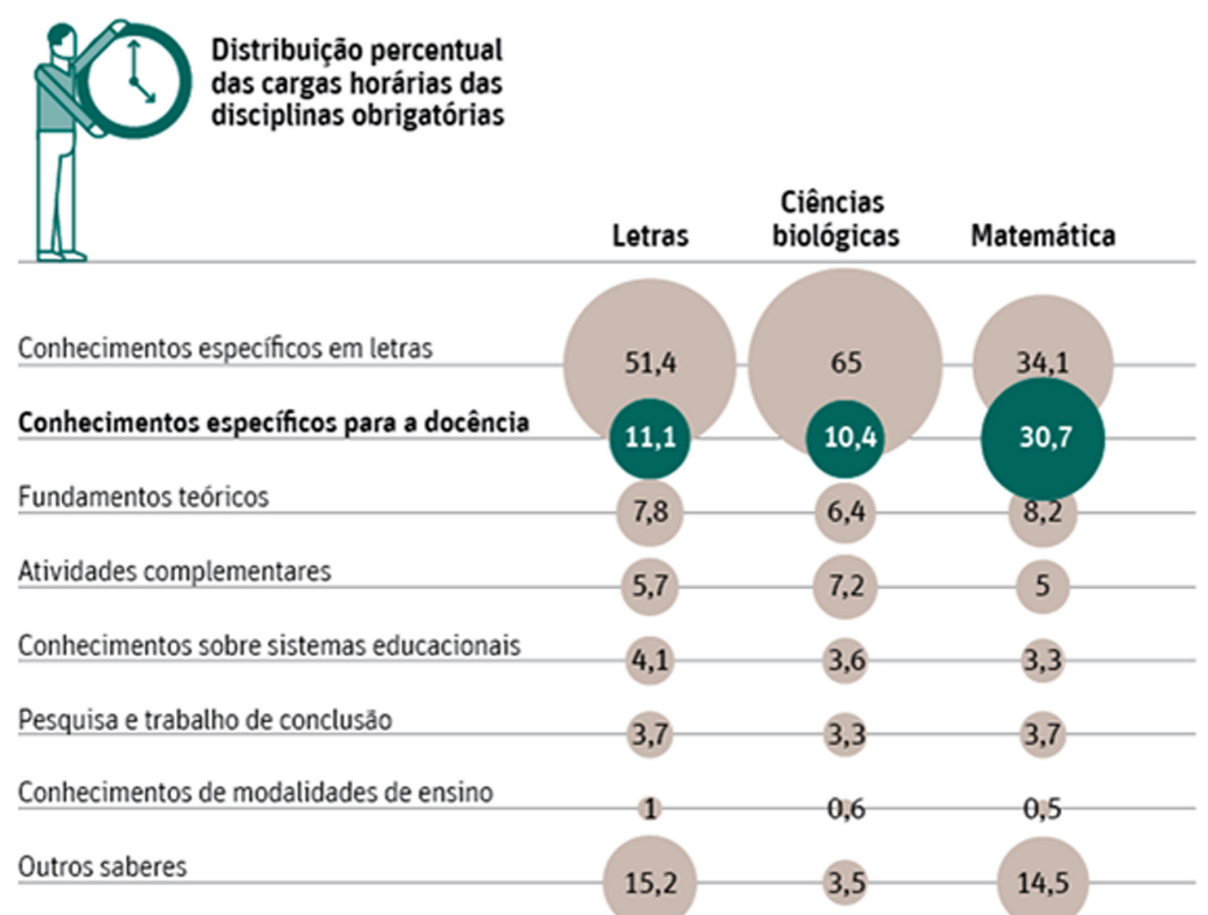

